\title{
PENGARUH VARIASI CAMPURAN PERTALITE DENGAN METHANOL (BLENDING) TERHADAP KINERJA MOTOR HONDA MEGAPRO 160 CC TAHUN 2007
}

\author{
Sendy Setiawan \\ Teknik Mesin, Fakultas Teknik \\ Universitas Maarif Hasyim Latif, Sidoarjo, Indonesia \\ e-mail : sendy-setiawan@student.umaha.ac.id
}

\begin{abstract}
ABSTRAK
Motor bakar adalah sebuah alat transportasi yang menggunakan bahan bakar minyak sebagai metode untuk mengoprasikannya. Semakin menipisnya bahan bakar minyak bumi maka saya tertarik untuk meneliti campuran bahan bakar pertalite dengan methanol (blending-B).Metodologi penelitian ini dilakukan secara exsperimental pada motor Honda Megapro 160 cc tahun 2007 dengan bahan bakar B100, B70, B60 dan B50 di kampus UNESA ketintang dan SMK PGRI 1 Sidoarjo untuk mengetahui pengaruh terhadap torsi, daya, konsumsi bahan bakar dan emisi gas buang. Hasil dari pengujian ini menunjukan nilai tertinggi torsi 7,73 Nm pada campuran B60 putaran 8580 rpm, daya 10,7 HP pada B60 putaran $11380 \mathrm{rpm}$, konsumsi bahan bakar paling hemat B50 padaputaran 2000 sampai 5000 rpm dibandingkan B100, B70 dan B60, sedangkan pengujian sisa hasil pembakaran yang paling ramah lingkungan pada B70 dengan kadar CO 5,1 \%vol dan HC 964,3 ppmvol.
\end{abstract}

Kata kunci: blending, methanol perfoma mesin, pertalite

\subsection{Latar Belakang}

\section{PENDAHULUAN}

Pada saat ini pemakaian motor menggunakan bahan bakar fosil dari hari ke tahun semakin meningkat cepat, hal ini mengakibatkan penggunaan bahan bakar fosil semakin membludak dan tentu sangat mengkhawatirkan karena dengan membludak penggunaan bahan bakar fosil maka cadangan akan semakin berkurang sedangkan kebutuhan akan minyak hasil bumi semakin terus bertambah pesat, minyak bumi merupakan salah satu bahan bakar fosil yang sering di gunakan dalam sehari-hari, kurangnya pemenuhan akan energi berpengaruh terhadap aktifitas untuk menjalankan berbagai kegiatan seperti transportasi.

Metanol adalah sebuah zat yang bisa dijadikan bahan bakar pada mesin pembakaran dalam dengan angka oktannya 105, sebagai senyawa methanol pada suhu 150c dapat dicampurkan dengan bahan bakar fosil yang disebut bioalkhol mampu menghasilkan suhu yang besar yang tidak dapat melewati $15 \%$, hal ini dikarenakan methanol bersifat polar sehingga kelarutan methanol rendah dalam senyawa alkane, Penggunaan metanol sebagai bahan bakar langsung hanya bisa dilakukan pada mesin khusus atau melakukan modifikasi pada mesin berbahan bakar bensin. Hal ini dilakukan karena metanol bersifat korosif. Untuk mengatasi hal ini maka dilakukan pencampuran metanol kedalam bahan bakar pertalite dengan kadar tertentu.

\subsection{Rumusan masalah}

Berdasarkan uraian latar belakang di atas, dapat diidentifikasikan beberapa masalah dalam penelitian ini di antaranya :

1. Bagaimana pengaruh campuran bahan bakar pertalite dan methanol (B100, B70, B60 dan B50) terhadap torsi, daya dan konsumsi bahan bakar.

2. Bagaimana pengaruh campuran bahan bakar pertalite dan methanol (B100, B70, B60 dan B50) terhadap emisi gas buang.

\subsection{Batasan masalah}

Agar penelitian yang dilakukan mengarah dan tidak menyimpang dari permasalahan yang diteliti, maka akan dibatasi permasalahannya pada :

1. Objek penelitian menggunakan bahan bakar pertalite dan methanol (B100, B70, B60 dan B50) sepeda motor Honda Megapro $160 \mathrm{cc}$ Tahun 2007.

2. Pengujian mesin pada dilakukan dengan menggunakan alat dynotest dalam keadaan menyala.

3. Pengujian konsumsi bahan bakar dilakukan dengan menggunakan campuran pertalite dan methanol (B100, B70, B60 dan B50) dari 2000 sampai $5000 \mathrm{rpm}$ pada kondisi mesin menyala.

4. Pengujian emisi gas buang menggunakan alat gas analyzer merk Qirotech pada kondisi mesin menyala.

\subsection{Tujuan}


Berdasarkan perumusan masalah, tujuan yang akan dicapai dalam penelitian ini adalah :

1. Mengetahui pengaruh campuran bahan bakar pertalite dan methanol

(B100, B70, B60 dan B50) terhadap torsi, daya dan konsumsi bahan bakar.

2. Mengetahui pengaruh campuran bahan bakar pertalite dan methanol (B100, B70, B60 dan B50) terhadap emisi gas buang.

\subsection{Manfaat}

Adapun manfaat yang diharapkan dari penelitian ini adalah sebagai berikut:

1. Diperolehnya gambaran tentang perfoma dan konsumsi bahan bakar yang di hasilkan dari penggunaan bahan bakar Pertalite dan blending bahan bakar Pertalite dengan Methanol pada motor Honda Megapro Tahun 2007.

2. Sebagai tambahan kajian pustaka yang berkaitan dengan sepeda motor.

\section{METODE PENELITIAN}

\subsection{Bahan}

Bahan - bahan yang di perlukan dalam melakukan penelitian ini yaitu sepeda motor Honda Megapro, methanol dan pertalite.

\subsection{Metode}

Siapkan pertamax dan methanol untuk di campurkan ke dalam botol bekas, siapkan kedua bahan tersebut untuk di blanding- $B$ dengan variasi B100, B70, B60, B50.

Ada beberapa hal yang saya teliti yaitu:

1. Mencari data daya, torsi motor menggunakan dynotest.

2. Mencari data konsumsi bahan bakar.

3. Mencari data emisi gas buang menggunakan gas anlyzer.

Langkah-langkah cara mencari data daya, torsi pada dynotest :

1. Menyiapkan kendaraan, bahan yang akan digunakan.

2. Selang yang ditangki kendaraan yang menuju ke karburator dilepas dan sambungkan ke selang dari fuel meter.

3. Mengisi gelas ukur pada fuel meter dengan pertamax secukupnya

4. Menyiapkan chassis dynamometer dan memastikan kondisi sesuai prosedur.

5. Memasang tali pengikat pada kendaraan.

6. Pasang inductive pickup sensor ke kabel koil.

7. Hidupkan komputer, Pilih program sport dyno 33 kemudian Pilih menu Options kemudian pilih configuration dan start motor.

8. Naikkan posisi gigi persneling secara bertahap sampai pada gigi 5 stabilkan putaran mesin pada $3000 \mathrm{rpm}$, lalu tekan tombol switch computer data acquisition satu kali.

9. Naikkan putaran mesin hingga mencapai $10.000 \mathrm{rpm}$ (perubahan putaran mesin dapat dilihat pada tachometer yang terdapat pada layar monitor), kemudian tekan tombol switch computer data acquisition untuk pengambilan data.

10. Pengambilan data pada tingkat putaran 3000 sampai $10.000 \mathrm{rpm}$ dengan rentang $500 \mathrm{rpm}$, data akan tersimpan di PC.

11. Putaran mesin diturunkan secara perlahan.

12. Mesin dan blower dimatikan.

Langkah-langkah cara mencari data konsumsi bahan bakar :

1. Kosongkan bahan bakar pada karburator.

2. Tancapkan selang bahan bakar fuel meter ke karburator.

3. Isi gelas ukur pada fuel meter dengan bahan bakar secukupnya.

4. Start mesin sepeda motor atur pada putaran stabil untuk tiap pengambilan data putaran mesin (2000-10000) dengan rentan Rpm 500'

5. Start mesin sepeda motor atur pada putaran stabil untuk tiap pengambilan data putaran mesin (2000-10000) dengan rentan Rpm 500.

6. Untuk mengkhiri percobaan ini, matikan mesin.

Langkah-langkah cara mencari data emisi gas buang :

1. Pengecekan pipa gas buang (tidak terdapat kebocoran).

2. Menyiapkan alat ukur uji emisi kendaraan sesuai standar ISO 3930/OIML R-99.

3. Memberi majun pada sambungan dan lubang pada knalpot agar tidak ada pemasukan udara pada sistem pembuangan.

4. Melakukan kalibrasi exhaust gas analyzer.

5. Menghidupkan mesin dan menjaga posisi temperatur mesin $60^{\circ} \mathrm{C}$.

6. Gigi transmisi pada posisi netral.

7. Memasukkan probe alat uji ke pipa gas buang sedalam $30 \mathrm{~cm}$ lalu tunggu 20 detik untuk pengambilan data konsentrasi gas CO dan CO2 dalam satuan persen ( $\%$ vol), dan HC dalam satuan ppm yang terukur pada alat uji.

8. Mencetak atau print hasil uji.

9. Melakukan percobaan untuk kelompok pemakaian campuran bahan bakar pertamax dan Methanol.

10. Putaran mesin diturunkan secara perlahan sampai putaran idle, dan untuk sesaat mesin dibiarkan pada putaran idle. Mesin dan Blower dimatikan.

\subsection{Tempat Penelitian}

Pengambilan data untuk pembuatan skripsi ini dilakukan di Laboratorium Pengujian Performa Mesin Gedung A8 Lt. 1 FT UNESA Jl. Ketintang 
Surabaya dan bengkel praktek SMK PGRI 1 Sidoarjo. Tempat ini dipilih karena peralatan sudah cukup lengkap dan memadai serta lebih efisien waktu untuk melakukan penelitian ini.

\subsection{Peralatan Uji}

Peralatan dan bahan yang digunakan dalam penelitian ini adalah sebagai berikut:

1. Tool set

Toolset terdiri dari kunci pas ring $8-24 \mathrm{~cm}$, obeng + , obeng -, dan kunci inggris.

2. Rpm counter

Alat yang digunakan untuk mengukur putaran yang dihasilkan mesin.

3. Chasis dynamometer adalah alat yang digunakan untuk mengukur torsi dan daya yang dihasilkan oleh mesin.

4. Stopwatch digunakan sebagai alat bantu dalam menghitung konsumsi bahan bakar pada saat pengujian.

5. Blower adalah alat yang digunakan untuk mendinginkan mesin sewaktu pergantian pengujian.

6. Fuel meter digunakan untuk menghitung kebutuhan bahan bakar minyak dalam satuan waktu.

Bahan bakar menggunakan blending Pertalite dan Methanol

1. Pertalite $70 \%: 30 \%$ Methanol

2. Pertalite $60 \%: 40 \%$ Methanol

3. Pertalite $50 \%: 50 \%$ Methanol

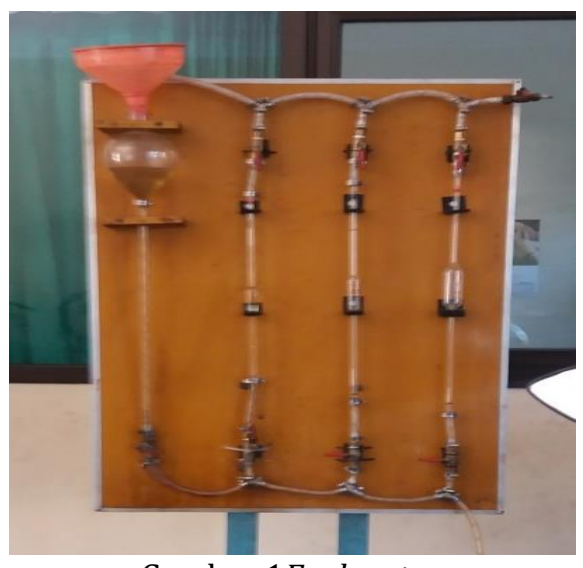

Gambar 1 Fuel meter

7. Exhaust gas analizer

Exhaust gas anlyzer adalah alat yang digunakan untuk mengukur kadar polutan gas buang yang merupakan hsail dari proses pembakaran mesin.

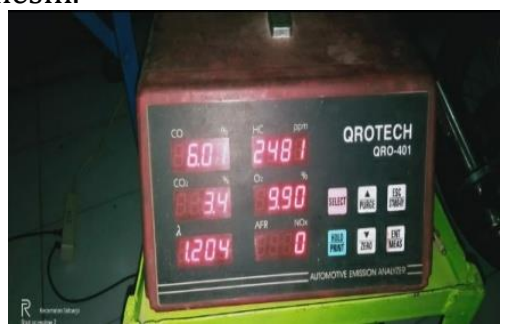

Gambar 2 Exhaust gas anlyzer

8. Sepeda motor Honda Megapro160 cc Tahun 2007

\subsection{Teknik Analisa Data}

Penelitian ini menggunakan metode deskriptif dengan mengumpulkan informasi atau data dari setiap hasil perubahan yang terjadi melalui eksperimen secara langsung. Metode ini dilakukan untuk memberikan gambaran terhadap perubahan yang terjadi setelah dilakukan penelitian. Data yang sudah terkumpul dimasukkan ke dalam tabel dan ditampilkan dalam bentuk grafik. Setelah dimasukkan ke dalam bentuk grafik data hasil penelitian dibandingkan antara kelompok standar dan eksperimen.

\section{HASIL DAN PEMBAHASAN}

\subsection{Uji Torsi dan Daya}

Tabel 1 Uji Torsi Dan Daya

\begin{tabular}{|c|c|c|c|c|c|c|c|c|c|c|}
\hline \multirow{2}{*}{ NO } & \multirow{2}{*}{$\begin{array}{c}\text { PUTARAN } \\
(\mathrm{rpm})\end{array}$} & $\begin{array}{c}\text { B10 } \\
0\end{array}$ & B70 & B60 & B50 & $\begin{array}{c}\text { B10 } \\
0\end{array}$ & B70 & B60 & B50 & $\begin{array}{c}\text { KE } \\
\text { T }\end{array}$ \\
\hline 1 & 8261 & 7,58 & & & & & & & & \\
\hline 2 & 10846 & & & & & 10,3 & & & & \\
\hline 3 & 8615 & & 7,72 & & & & & & & \\
\hline 4 & 11220 & & & & & & 10,6 & & & \\
\hline 5 & 8580 & & & 7,73 & & & & & & \\
\hline 6 & 11380 & & & & & & & 10,7 & & \\
\hline 7 & 8316 & & & & 7,57 & & & & & \\
\hline 8 & 11270 & & & & & & & & 10,5 & \\
\hline
\end{tabular}

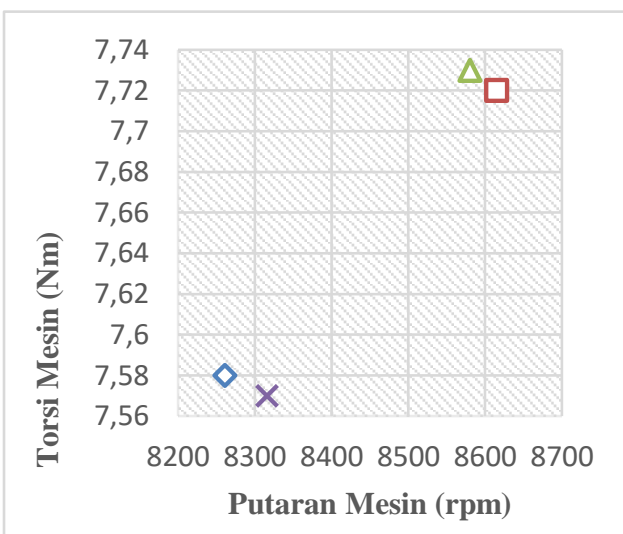

$\diamond$ TORSI (Nm) B100 पTORSI (Nm) B70

$\triangle$ TORSI (Nm) B60 XTORSI (Nm) B50

Gambar 3 Uji Torsi

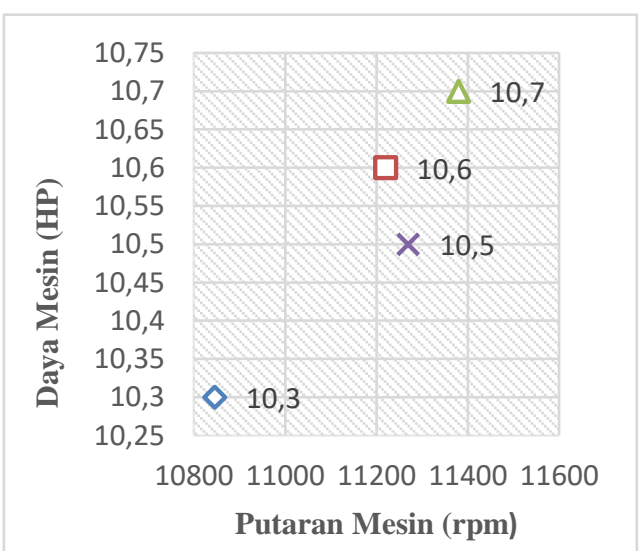




\section{Grafik 4. Uji Daya}

Berdasarkan hasil tabel dan grafik pengujian diatas didapatkan perbedaan torsi antara variasi campuran bahan bakar Pertalite dan Methanol B100, B70, B60, B50. Torsi yang menggunakan variasi campuran bahan bakar B60 pada putaran 8580 yaitu 7,73 $\mathrm{Nm}$ cenderung lebih tinggi dari pada torsi yang menggunakan variasi campuran bahan bakar B100, B70, B50, sedangkan variasi campuran bahan bakar Pertalite dan Methanol B100 pada putaran $8261 \mathrm{rpm}$ yaitu 7,58 Nm, variasi campuran bahan bakar B70 pada putaran $8615 \mathrm{rpm}$ yaitu 7,72 Nm dan untu variasi campuran bahan bakar B50 pada putaran $8316 \mathrm{rpm}$ yaitu 7,57 Nm.

Berdasarkan hasil tabel pengujian diatas didapatkan perbedaan daya antara variasi campuran bahan bakar Pertalite dan Methanol B100, B70, B60, B50. Daya yang menggunakan variasi campuran bahan bakar B40 pada putaran $11380 \mathrm{rpm}$ yaitu 10,7 HP cenderung lebih tinggi dari pada daya yang menggunakan variasi campuran bahan bakar B100, B70, B50, sedangkan variasi campuran bahan bakar Pertalite dan Methanol B100 pada putaran $10846 \mathrm{rpm}$ yaitu 10,3 HP, variasi campuran bahan bakar B70 pada putaran $11220 \mathrm{rpm}$ yaitu 10,6 HP, variasi campuran bahan bakar B50 pada putaran $11270 \mathrm{rpm}$ yaitu 10,5 HP.

\subsection{Gas Buang}

\begin{tabular}{|c|c|c|c|c|c|c|}
\hline \multirow{2}{*}{ N0 } & Kandungan Gas & \multirow{2}{*}{ Satuan } & \multicolumn{4}{|c|}{ Variasi Campuran } \\
\cline { 4 - 7 } & Buang & & B100 & B70 & B60 & B50 \\
\hline 1 & $\mathrm{CO}$ & $(\% \mathrm{Vol})$ & 7,11 & 6,55 & 6,29 & 5,82 \\
\hline 2 & $\mathrm{C} 02$ & $(\% \mathrm{Vol})$ & 5,17 & 5,1 & 4,77 & 5,5 \\
\hline 3 & $\mathrm{HC}$ & $(\mathrm{ppmV}$ ol $)$ & 1057 & 964,3 & 988,7 & 986,3 \\
\hline 4 & 02 & $(\% \mathrm{Vol})$ & 8,647 & 7,473 & 8,14 & 7,737 \\
\hline 5 & Nox & $(\% \mathrm{Vol})$ & 0 & 0 & 0 & 0 \\
\hline 6 & Lambda & & 1,178 & 1,108 & 1,161 & 1,167 \\
\hline
\end{tabular}

Tabel 2. Emisi Gas Buang

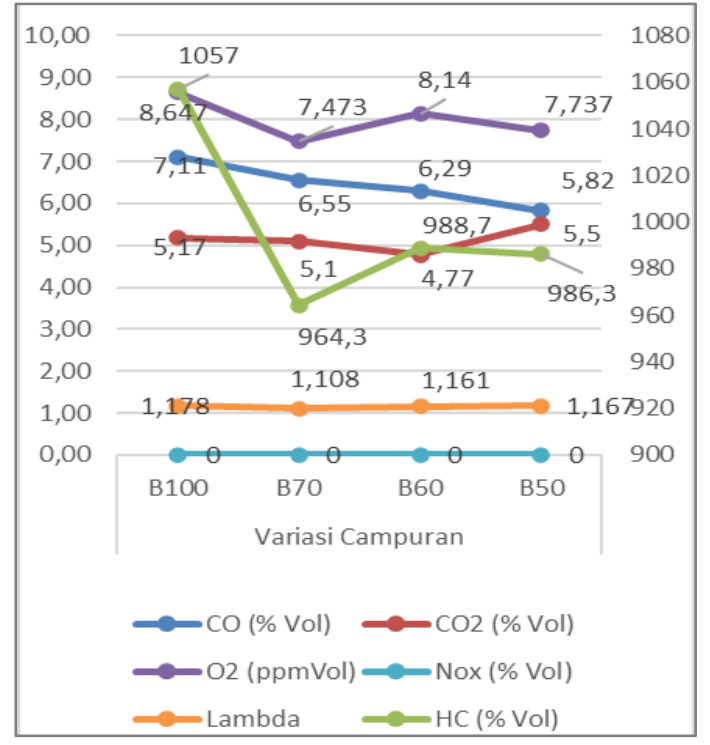

Grafik 5. Uji Gas Buang

Hasil olah data pada tabel dan grafik menunjukan bahwa ada perbedaan hasil analisa gas buang rata - rata antara variasi campuran bahan bakar B100, B70, B60 dan B50 pada sepeda motor Honda Megapro 160 cc tahun 2007. Hasil dari variasi campuran B100 menghasilkan rata - rata kadarCO $\mathrm{CO}_{2}$ 5,17\%vol dan kadar HC 1057 ppmvol, variasi bahan bakar B70 menghasilkan rata - rata kadar $\mathrm{CO}_{2}$ 5,1 \%vol dan kadar HC 964,3 ppmvol, variasi bahan bakar B60 menghasilkan rata - rata kadar $\mathrm{CO}_{2}$ 4,77 \%vol dan kadar $\mathrm{HC} 988,7$ ppmvol, variasi campuran B50 menghasilkan rata - rata kadar $\mathrm{CO}_{2}$ 5,5 \%vol dan kadar HC 986,3 ppmvol. Berdasarkan data di atas dapat disimpulkan penggunaan variasi campuran bahan bakar B70 (70\% Pertalite : 30\% Methanol) terjadi proses pembakaran paling sempurna dibandingkan variasi campuran bahan bakar B100, B60 dan B50.

\subsection{Analisa Konsumsi Bahan Bakar}

Dengan metode yang sama dengan rumus diatas maka didapatkan nilai konsumsi bahan bakar untuk masing - masing variasi blending bahan bakar B100, B70, B60, B50. Untuk mendapatkan nilai konsumsi bahan bakar dapat di gunakan rumus sebagai berikut

$$
F C=\frac{b}{t} \cdot y f \cdot \frac{3600}{1000} \cdot \frac{\mathrm{kg}}{\mathrm{jam}}
$$

Keterangan :

Fc = Konsumsi bahan bakar $[\mathrm{kg} / \mathrm{jam}]$

$\mathrm{b}=$ Volume bahan bakar [ml]

$\mathrm{t}=$ Lama waktu komsumsi bahan bakar [det]

yf 


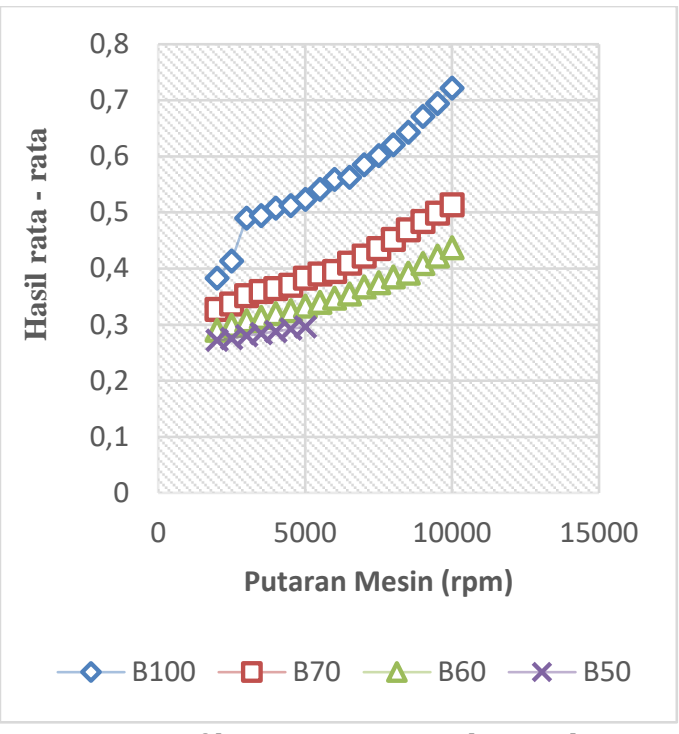

Grafik 6. Konsumsi Bahan Bakar

Tabel 3. Konsumsi Bahan Bakar

\begin{tabular}{|c|c|c|c|c|}
\hline \multirow{2}{*}{ Rpm } & \multicolumn{4}{|c|}{ Fc variasi campuran } \\
\cline { 2 - 5 } & B100 & B70 & B60 & B50 \\
\hline 2000 & 0,383 & 0,327 & 0,29 & 0,272 \\
\hline 2500 & 0,413 & 0,337 & 0,299 & 0,275 \\
\hline 3000 & 0,49 & 0,352 & 0,307 & 0,28 \\
\hline 3500 & 0,494 & 0,359 & 0,313 & 0,284 \\
\hline 4000 & 0,508 & 0,364 & 0,32 & 0,288 \\
\hline 4500 & 0,512 & 0,37 & 0,325 & 0,292 \\
\hline 5000 & 0,523 & 0,383 & 0,333 & 0,296 \\
\hline 5500 & 0,541 & 0,39 & 0,34 & \\
\hline 6000 & 0,559 & 0,395 & 0,347 & \\
\hline 6500 & 0,563 & 0,41 & 0,355 & \\
\hline 7000 & 0,585 & 0,422 & 0,367 & \\
\hline 7500 & 0,601 & 0,436 & 0,375 & \\
\hline 8000 & 0,621 & 0,452 & 0,385 & \\
\hline 8500 & 0,643 & 0,469 & 0,392 & \\
\hline 9000 & 0,671 & 0,484 & 0,409 & \\
\hline 9500 & 0,694 & 0,499 & 0,422 & \\
\hline 10000 & 0,722 & 0,514 & 0,437 & \\
\hline Rata-rata Fc & 0,474714 & 0,356 & 0,312429 & 0,283857 \\
\hline
\end{tabular}

Dari hasil tabel dan grafik komsumsi variasi campuran bahan bakar di atas didapat hasil rata rata dari campuran variasi B100, B70, B60, B50 pada sepeda motor Honda Megapro 160 cc tahun 2007. Hasil variasi campuran B100 rata - rata 0,474 $\mathrm{kg} / \mathrm{jam}$, variasi campuran $\mathrm{B} 70$ rata - rata 0,356 $\mathrm{kg} / \mathrm{jam}$, variasi campuran B60 rata - rata $0,312 \mathrm{~kg} / \mathrm{jam}$, variasi campuran $\mathrm{B} 50$ rata - rata $0,283 \mathrm{~kg} / \mathrm{jam}$.
Berdasarkan data diatas didapatkan data variasi B50 (50\% Pertalite : 50\% Methanol) lebih irit dari varasi campuran B100, B70, B60 yaitu rata - rata fc 0,283 kg/jam, tetapi karena uji M50 hanya bisa sampai rpm 5000 maka diambil uji M40 yang lebih irit dari yang lain dengan rata - rata fc 0,312 $\mathrm{kg} / \mathrm{jam}$.

\section{PENUTUP}

\subsection{Kesimpulan}

Berdasarkan analisa hasil pengujian variasi blending Pertalite dengan Methanol B100, B70, B60 dan B50 pada sepeda motor Honda Megapro 160 cc tahun 2007, dapat di simpulkan beberapa hal sabagai berikut :

1. Dari uji torsi dan daya variasi campuran bahan bakar Pertalite dan Methanol pada motor Honda Megapro 160 cc tahun 2007 dengan melakukan 3 kali pengujian di dapatkan hasil rata - rata paling maksimal pada variasi campuran bahan bakar B60.Dari hasil uji konsumsi bahan bakar pada variasi campuranbahan bakar Pertalite dan Methanol pada motor Honda Megapro $160 \mathrm{cc}$ tahun 2007 B50 hemat dari pada B100,B70 dan B60.

2. Berdasarkan data di atas dapat disimpulkan penggunaan variasi campuran bahan bakar B70 lebih ramah lingkungan dibandingkan B100, B60 dan B50

\subsection{Saran}

Saran yang bisa saya berikan sebagai upaya untuk perbaikan pada peneliti selanjutnya yaitu :

1. Sebelum melakukan pengujian kondisi motor harus dalam keadaan optimal, dicek terlebih dahulu untuk meminimalis kendala saat melakukan pengujian.

2. Mempersiapkan variasi blending sebelum melakukan pengujian, Karena hal tersebut dapat memperlambat waktu dalam proses pengujian.

\section{DAFTAR PUSTAKA}

Afifah, Y. N. (2016). ALIRAN TAK TUNAK FLUIDA NANO MAGNETOHIDRODINAMIK ( $M H D$ ) YANG MELEWATI BOLA.

Afifah, Y. N. (2019). (2019). Analysis of Unsteady Magneto Hydro Dynamic ( MHD ) Nano Fluid Flow Past A Sliced Sphere Analysis of Unsteady Magneto Hydro Dynamic ( MHD ) Nano Fluid Flow Past A Sliced Sphere. IOP Conference Series: Materials Science and Engineering, 494, 012033. https://doi.org/10.1088/1757899X/494/1/012033 
Afifah, Y. N., \& Putra, B. C. (2018). Model Matematika Aliran Tak Tunak Pada Nano Fluid Melewati Bola Teriris Dengan Pengaruh Medan Magnet. Teknika: Engineering and Sains Journal, 2(2), 119-124.

Agrariksa, F. A., Susilo, B., \& Nugroho, W. A. (2013). Uji Performansi Motor bakar Bensin ( On Chassis) Menggunakan Campuran Premium dan Refbacks.

Ariawan, I. W. B., Kusuma, I. G. B., \& Adnyana, I. W. B. (2016). Pengaruh Penggunaan Bahan Bakar Pertalite Terhadap Unjuk Kerja Daya, Torsi, Dan Konsumsi Bahan Bakar Pada Sepeda Motor Bertransmisi Otomatis. Jurnal METTEK.

Gunawan, E., Choifin, M., Khoirul Rosidin, M., Nur Afifah, Y., Lestariningsih, W., Sungging Pradana, M., ... Makki, A. (2019). Analysis of the Effect of Current Flow Variations in GTAW on SS 400 Plate Material Connected with SUS 304 Stainless Steel Plate Against Tensile Strength and Hardness with ER308L Electrodes. Journal of Physics: Conference Series, $1175(1)$. https://doi.org/10.1088/17426596/1175/1/012277

Ilham, M. (2016). Pengaruh Bahan Bakar Pertalite Dan Premium Terhadap Performa Mesin Motor Yamaha Jupiter Z - Cw Tahun 2010. Mechanical Engineering Machinery.

Menu, M. (2014). Pengaruh Penggunaan dan Perhitungan Efisiensi Bahan Bakar Premium dan Pertamax Terhadap Unjuk Kerja Motor Bakar Bensin Refbacks.

Saragih, R., Saragih, R., \& Kawano, D. S. (2013). Pengaruh Penggunaan Bahan Bakar Premium, Pertamax, Pertamax Plus Dan Spiritus Terhadap Unjuk Kerja Engine Genset 4 Langkah. Jurnal Teknik ITS. https://doi.org/10.12962/j23373539.v2i1.2 791

Yunita Nur Afifah, MNH Qomarudin, \& Imamatul Ummah. (2020). Optimal Control Model Pemanenan Prey-Predator di Area Konservasi Ikan. Buana Matematika : Jurnal Ilmiah Matematika Dan Pendidikan Matematika, 10(1), 1-16. https://doi.org/10.36456/buanamatematik a.v10i1.2410 